\title{
CRIPTOCOCOSIS Y TOXOPLASMOSIS EN UN PACIENTE CON ENFERIMEDAD DE HODGKIN
}

\author{
Adoración Duarte, $V^{*}$, Miguel Suárez, $H^{* *}$, \\ Roberto Peláez, $\mathbf{M}^{* * *}$, Albadio Peréz, $\mathbf{A}$ **** \\ *Hospital Provincial "Antonio Luaces Iraola", Provincia Ciego de Avila ,CUBA \\ ${ }^{* *}$ CentroProv. DeHigiene y Epiderniología, ${ }^{* * *}$ Hospital Psiquiátrico, \\ **** Hospital Nacional, Ciudad de la Habana
}

Palabras clave: Toxoplasmosis, Criptococosis, Hodgkin. Key words: Toxoplasmosis, Cryptococcosis, Hodgkin.

\section{RESUMEN}

Se presenta un caso clinico de un paciente de 35 años con enfermedad de hodgkin, con 5 años de evolución que presentó un cuadro sugestivo de encefalitis viral. Se detectó un título de 1/2048 en la inmunofluorescencia para Toxoplasma. El paciente falleció al cabo de 18 dias de evolución. Se confirmó además una criptococosis en la necropsia.

La enfermedad de Hodgkin es un cáncer originado en el tejido linfoide, que tiene algunas características que lo diferencian de otros linfomas: a) la histología del tumor muestra una mezcla desorganizada de células de apariencia normal (linfocitos, eosinófilos, células plasmáticas) con células malignas ( gigante multinucleada o mononucleada) b) tiene posibilidad de curación en alrededor del $70 \%$ de los casos, c) se caracteriza por la presencia de células gigantes poliploides de origen no definido, conocido como células de Reed-Sternber (1).

Esta entidad es poco frecuente y representa el 1\%de todosloscánceres. Su incidencia anual es de aproximadamente 30 casos por millón y puede afectar a individuos de cualquier raza, edad o sexo, aunque la mayoría de los casos se presentan entre los 20 y 40 años, en el hombre, su frecuencia es algo mayor que en la mujer, (2). En la enfermedad de hodgkin se produce una inmunodeficiencia multifactorial donde convergen la propia enfermedad, la terapeútica y en algunos casos la esplenectomía. Esto hace que los pacientes sean vulnerables a diversos agentes oportunistas, así como a infecciones por gérmenes encapsulados debido al daño en la inmunidad celular y humoral. (3).

La criptococosis, se instala muchas veces en pacientes debilitados por otras enfermedades (desórdenes del sistema reticuloendotelial, en especial enfermedad de hodgkin y' por tratamiento con corticoesteroides), el período

\section{SUMMARY}

/Cryptococcosis and Toxoplasmosis in a patient with Hodgkin disease]

A clinical case of a patient 35 years old with Hodgkin disease of 5 years evolution, with a picture suggestive of viral encephalitis was presented. A title of $1 / 2048$ in inmunofluorescence of Toxoplasma was detected. The patient died within 18 days of evolution. Besides a cryptococcosis in the autopsy was confirmed.

de incubación es desconocido, la lesión pulmonar puede preceder a la cerebral por meses o años. (4).

La toxoplasmosis en su forma ganglionar es la más frecuente y en su diagnóstico diferencial debe tenerse en cuenta la mononucleosisy otras enfermedades que producen adenopatía, entre ellas la fase inicial de los enfermos de hodgkin ( 5 y 6 ).

Diferentes autores han señaladola presencia de toxoplasmosis en pacientes con linfomas de hodgkin. También se ha reportado en ocasiones, la asociación de criptococosis y toxoplasmosisen pacientesinmunocomprometidos $(7,8)$.

En la literatura cubana revisada no hemos èncontrado lapublicación deningún casode linfoma de hodgkin asociado con criptococosis y toxoplasmosis, por locual consideramos útil presentar el siguiente reporte.

\section{PRESENTACION DEL CASO}

Paciente A.L.C, 35 años, sexo masculino, que ingresó el día 10-2-89 al servicio de medicina del hospital provincial "Antonio Luaces Iraola", de la provinvia Ciego de Avila,con historia clínica ${ }^{\circ} 364647$. El paciente presentaba linfoma de hodgkin de 5 años de evolución por lo cual recibió tratamiento con citostáticos y radioterapia. Acudió con cefalea intensa, fiebre de 38 grados y compromiso 
del estado general de un mes de duración, por lo cual concurrió varias veces al cuerpo de guardia. Al examen físico presentó rigidez de nuca, algunos signos de kerning positivos, adenopatía cervical y hepatoesplenomegalia. El paciente presentaba también ictiosis adquirida. Sepracticó punción lumbar, detectándose 600 célulasen el líquido cefaloraquídeo con predominio de linfocitos. Se plantea como diagnósticao presuntivo, meningoencefalitis viral. En los exámenes complementarios realizados, se obtuvouna ligera leucocitosis con eosinofilia del $6 \%$ y la eritrosedimentación era elevada $(50 \mathrm{~mm}$.).

Se inicia tratamiento sintomático. Al cabo de 2 días presenta intensos mareos, naúseasy vómitos. Al cabode 10 días presenta opistotono, fotofobia y débil respuesta a los reflejos. Se mantuvo nuevamente el diagnóstico de una encefalitis viral.

Seindicó un exámen de inmunofluorescencia para Toxoplasma. El paciente fallece al cabo de 18 días de su ingreso, el mismo día de su fallecimiento se recibe el resultado de la inmunofluorescencia, cuyos títulos fueron 1/ 1024 , con IGM positiva.

En la histopatología de la necropsia, se detectó:

1. Meningitis criptocosica

2. Toxoplasmosis del encéfalo

3. Enfermedad de hodgkin, tipodepresión linfocítica. con infiltración esplénica.

4.Bronconeumonia bilateral.

5. Gastritis aguda.

\section{DISCUSION}

Se señala que la infección por Cryprococcus neof ormarss, es dosveces más frecuenteen el sexo masculino que en el femenino, predominando en los adultos(9). En la provincia Ciego de Avila, de la República de Cuba, han ocurrido dos casos de criptococosis entre el período de 1980 a 1992, uno era un paciente inmunocompetentey en nuestro caso inmunodeficiente, ambos eran adultos del sexo masculino, loscuales fallecieron.

Con respecto a la frecuencia de la criptococosis, se señala que la forma meningo encefálica tiene baja frecuencia, mientras la forma respiratoria es la más común, pero se diagnostica con menos frecuencia que la anterior (10).

Los dos casos diagnosticados en la provincia Ciego de Avila han presentado localización en el sistema nervioso central. Uno de los pacientes era criador de palomas (el inmunocompetente) y el otro no tenía exposición conocida a excretas de palomas o de aves.

\section{AGRADECHMILNTOS}

Se agradece la colaboración prestada a las Dras. María Victoria, Ester Estrada, Gladys Taño, al Dr. Alfredo Estrada y al Licenciado Ernesto Salcedo.

\section{REFIRENCIAS}

1. Carnot, J. (1989). La enfermedad de hodgkin, aspectos clinicos, biologicos y terapeúticos (Revisión). Act. Med. Hosp. Alm. 3: $96-135$

2. Jandi, H.H. (1987). Hodgkin disease. Blood testbook of hematology'. Little Brown Company, Boston.

3. Regula, D. P. (1988). Nodular and diffuse types of limphocyte predominance, hodgkins disease. New. Engl. J. Med. 318:214219.

4. Acha, P. \& Szyfres, B. (1986). Zoonosis y enfermedades transmisibles comunes al hombre y a los animales. Segunda edición. Publicación cientifica $N^{\circ}$ 503. Editorial OPS, Washington.

5. Suárez, M. (1988). Diagnóstico serológico de formas ganglionares de la toxoplasmosis. Rev. Cub. Med. Top. 38:209-215.
6. Soto, R. \& Tarazón de Sof́, S. (1990). Tratamiento y evolución de la toxoplasmosis, ganglionar, Kasmera. Vol. 18:1-8.

7. Beneson, A. (1987). El control de las enfermedades trasmisibles en el. hombre. Publicación cientifica $N^{\circ} 507$. Editorial OPS, Washington.

8. Zapater, R.(1973). Atlas de diagnóstico micológico 3ra. Edición. Edición Revolucionaria, La Habana.

9. Hoeprich, P. (1982).Tratado de enfermedades infecciosas. Vol 2. Editorial Cientifico Técnica, Ciudad La Habana."

10. Goderich, $\mathbb{R}$. (1976). Temas de medicina interna. Vol.2. Edición Revolucionaria, Ciudad La Habana. 